\title{
The 2019 International Workshop on Statistical Genetic Methods for Human Complex Traits March 4th-March 8th, 2019
}

(c) Springer Science+Business Media, LLC, part of Springer Nature 2018

The next workshop will be held in Boulder, Colorado, March 4th-8th, 2019, with John Hewitt and Matt Keller as Local Hosts, and Benjamin Neale, Broad Institute and Massachusetts General Hospital, and David Evans, Diamantina Institute, University of Queensland, as co-Directors. This advanced course is intended for those who are already familiar with the statistical and genetic principles for studying human complex traits and have some familiarity with programming in $R$. The course will focus on statistical methods for analyzing genome-wide association studies (GWAS) and genome sequence data. Hands-on analysis will be an integral part of the course and will employ networked notebook computers. A provisional schedule is posted on the workshop website via https://www.colorado.edu/ibg/workshop-2019.

The registration fee is $\$ 600$, payable by January 25 th, 2019. Thereafter, the fee will be $\$ 700$. Non-payment by February 15th, 2019, will result in your registration being dropped, and cancellations after that date will be nonrefundable. Refunds of payments will incur a $\$ 25$ refund processing fee. Details of local arrangements, registration, and accommodation are available from the workshop secretary, Katie Sheehan, and at https://www.colorado.edu/ibg/ workshop-2019.

An outstanding international faculty roster includes:

Ben Neale (co-Director), Cotton Seed, Tim Poterba. Broad Institute and $M G H$

David Evans (co-Director). Diamantina Institute, University of Queensland
Goncalo Abecasis, University of Michigan and Regeneron Pharmaceuticals

Nick Martin, Sarah Medland, Katrina Grasby. Queensland Institute for Medical Research

Loic Yengo Dimbou, University of Queensland

Stacey Cherny, Tel Aviv University

Abdel Abdellaoui, Meike Bartels, Dorret Boomsma, Michel Nivard, Aysu Okbay, Danielle Posthuma, Jenny van Dongen, Kyoko Watanabe. Amsterdam Vrije Universiteit

John Hewitt (Local Host), Luke Evans, Matt Keller (Local Host), Jeff Lessem, Institute for Behavioral Genetics

Hermine Maes. Mike Neale. Virginia Institute for Psychiatric and Behavioral Genetics

Hilary Martin, Wellcome Sanger Institute.

Further information may be obtained from John Hewitt, or the workshop secretary, Katie Sheehan, IBG, University of Colorado, Boulder, CO 80309-0447, USA; Telephone: 303-492-3405; FAX: 303-492-8063; E-mail: John.Hewitt@ Colorado.edu or Catlin.Oleary@colorado.edu.

Individuals from underrepresented racial and ethnic groups, individuals with disabilities, and individuals from socially, culturally, economically, or educationally disadvantaged backgrounds are especially encouraged to attend. Partial financial support for US participants from these groups is available by application to the local host, John Hewitt.

Financial support for this workshop is provided by Grant MH19918 from the National Institute of Mental Health. 